\title{
A Study on TID and SEL tests on PWM-IC Controller of DC/DC Power Buck Converter
}

\author{
Young Hwan Lho ${ }^{1}$ and Surender Reddy Salkuti ${ }^{2}$ \\ ${ }^{1}$ Department of Railroad Electricity System, Woosong University, Daejeon, Korea \\ ${ }^{2}$ Department of Railroad Electricity System, Woosong University, Daejeon, Korea \\ ${ }^{1}$ yhlho@wsu.ac.kr, ${ }^{2}$ salkuti.surenderreddy@gmail.com
}

\begin{abstract}
The radiation hardening parts in space systems should be used since there exist various kinds of radiation particles in space environment. The radiation technology is very important for the localization of electronic parts for the next generation of satellites to come. The DC/DC switching power converters are commonly used to generate a regulated DC output voltage with high efficiency. The DC/DC converter is composed of a pulse width modulation-integrated circuit (PWM-IC) controller, a metal-oxide semiconductor field effect transistor (MOSFET), an inductor, and a capacitor, etc. The $P W M$ is applied to control and regulate the total output voltage. Radiation has the major influence on the changes in the electrical characteristics of PWM-IC. In PWM operation, the missing pulses and the changes in pulse width are studied by the simulation program with an integrated circuit emphasis (SPICE), Total Ionizing Dose (TID) and Single Event Latch-up (SEL) tests are accomplished and analyzed.
\end{abstract}

Keywords: DC/DC buck converter, PWM-IC, radiation effects, TID, SEL

\section{Introduction}

Space systems must withstand the effects of natural radiation environments having electrons and protons. Designing systems to withstand the effects of these radiation environments has been named as "hardening". For the past five decades, the country's with advance of satellite technology have been doing research on the field of radiation hardening of passive and active components for space and defense, and at the level of stabilization. However, our country, Korea, is the beginning stages of satellite technology. Most of the electronic components are affected by radiation to some extent. A pulse width modulation-integrated circuit (PWM-IC) controller designed by CMOS technology for DC/DC converter is damaged by radiation effects.

The two main categories of radiation effects are total ionizing dose (TID) and single event effects (SEE). TID had cumulative long term circuit degradation caused primarily by abundant ionizing electrons and protons. SEE has phenomenon producing from the action of ionizing particles including protons, electrons, and heavy ions penetrating sensitive nodes in circuit devices. SEE is classified as single event upset (SEU) showing state change of a memory bit, single event transient (SET) having erroneous pulse generation and propagation, single event latch-up (SEL) representing high current latching state, and multi-bit upset (MBU) making several memory bits change state by same ion, etc.

The primary sources of the ionizing radiation [1] near earth are from the Sum in the form of a solar wind of charged particles outflowing from the Sun's corona, which includes electrons, protons, and heavy ions, trapped particles in earth's magnetosphere, and Galactic Cosmic Ray ions.

The DC/DC switching power converter [2] shown in Figure 1 produces DC output voltage from different input sources. In a DC/DC converter with a given input voltage, the 
average output voltage is controlled by controlling the switch on and off durations ( $t_{\text {on }}$ and $t_{\text {off }}$ ). When the switch is on for a time duration $t_{\text {on }}$, the switch conducts the inductor current and the diode becomes reverse biased. A positive voltage across the inductor is given by

$$
v_{L}=V_{d}-V_{\text {out }}
$$

where $V_{d}$ is the voltage across the diode and $V_{\text {out }}$ is the output voltage of converter. The voltage makes a linear increase in the inductor current $i_{L}$. When the switch is off, the current flows through the diode and the voltage across the inductor becomes to

$$
v_{L}=-V_{\text {out }}
$$

In addition, DC/DC converters are commonly used to provide noise isolation, and power bus regulations. The switching power converter [3,4] uses energy storage elements such as capacitors or inductors to transfer energy from the input to the output at periodic intervals. This energy transfer results in a change in the DC output voltage relative to the input voltage, producing electrical isolation between the input and the output. DC/DC switching power converters are being applied for motor drives, computers, telecommunications, spacecraft power systems, and military and industrial applications. The ideal DC/DC converter exhibits $100 \%$ efficiency, but in practice the efficiency is 70 to $95 \%$. The total input power is dissipated at both metal-oxide semiconductor field effect transistor (MOSFET) and pulse width modulation-integrated circuit (PWM-IC).

There are three kinds of main DC/DC converters exist: a) A buck converter as a stepdown converter is used for cases in which a lower output voltage than input is required; $b$ ) the boost converter as a step-up converter is used for cases in which higher output voltage than input is required; c) a buck-boost converter, which reduces or increases the voltage ratio with a unit gain for a duty ratio of $50 \%$. This paper focuses on the buck converter [5] by using of switched-mode power supply (SMPS). Typically, PWM-IC operates on either a current mode or a voltage mode. This study deals with the voltage mode in pulse width modulation. The problem of stored inductive energy is overcome by using a diode. The output voltage fluctuations are greatly diminished by using of a low pass filter, consisting of an inductor and a capacitor.

The greater the capacitance, and the greater the load resistance, the smaller the ripple effect becomes, which is measured at the output of the PWM and the boost converter. The output voltage of the ideal boost converter [6] is provided by

$$
V_{\text {out }}=\frac{1}{1-D} V_{\text {in }}
$$

where ${ }^{\mathrm{D}}$ is the duty ratio, which is defined as the ratio of the on duration to the switching time period, is varied.

The voltage mode PWM buck converter is consisted of the same components as the boost converter. However, the locations of MOSFET, diode, capacitor, and inductor differ. The output voltage of the ideal buck converter is given by

$$
V_{\text {out }}=\mathrm{DV}_{\text {in }}
$$

where the duty ratio is dynamically adjusted by the feedback circuit to keep a stable DC output voltage. Note that $\mathrm{D}$ is between 0 and 1 , and an output voltage decreases for the buck converter.

The power [5,7] consumed in PWM-IC is computed as follows.

$$
\mathrm{P}_{\mathrm{pwm}}=\left(\mathrm{I}_{\mathrm{c}}+\mathrm{f} \times \mathrm{Q}_{\mathrm{g}}\right) \mathrm{V}_{\mathrm{in}}
$$

where $I_{c}$ is the current of $14 \mathrm{~mA}$ flowing in the PWM-IC of SG1525A voltage mode, $\mathrm{f}$ is the frequency with a value of $85 \mathrm{Khz}$, and $\mathrm{Q}_{\mathrm{E}}$ is the gate charge with a value of $120 \mathrm{nC}$ for turning-on the MOSFET. The output power is obtained by,

$$
\mathrm{P}_{\mathrm{L}}=\frac{\mathrm{v}_{\text {out }}^{2}}{\mathrm{R}_{\mathrm{L}}}
$$




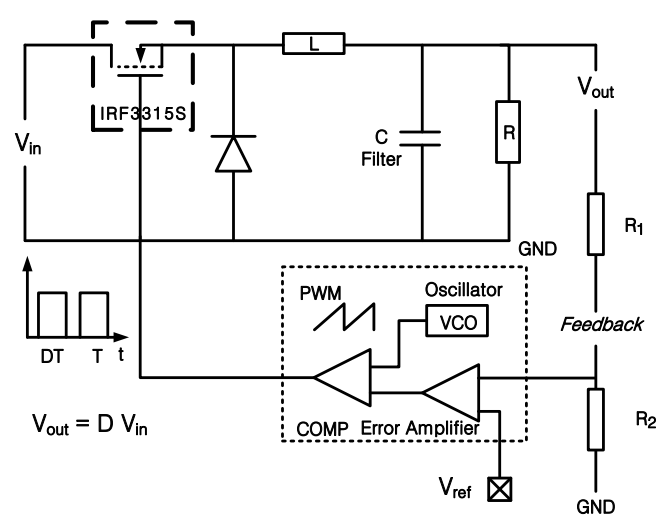

Figure 1. Block Diagram of DC/DC Buck Converter

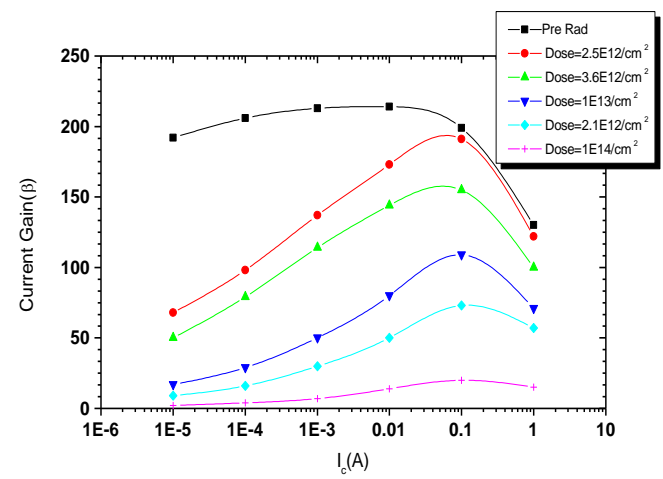

\section{Figure 2. Current Gain $(\beta)$ vs. Collector Current $\left({ }^{I_{C}}\right)$ for Different Neutron Dose}

For radiation environments, the current gains of $\beta$ shown in Figure 2 at a transistor decrease as neutron dose increases. Many experimental results in the technical paper [8] were suggested for estimating the relationship between the current gain $(\beta)$ and the dose. The characteristic model is considered before doing irradiation test of transistor P-SPICE [9], the circuit simulator of Microsim when the bipolar transistor is irradiated to neutron. The value of $\beta$ for pre-irradiation is, in general, more than 150 , the one of $\beta$ has tendency of decreasing to 30 in NPN transistor, and to 20 in PNP transistor for more than the dose of $1 \mathrm{Mrad}$. When the transistor is irradiated under neutron, Messenger-Spratt [10] characterizes as

$$
\frac{1}{\beta_{\text {post }}}=\frac{1}{\beta_{\text {pre }}}+10^{-7} \frac{\Phi_{\mathrm{n}}}{f_{\mathrm{T}}}
$$

where $\beta_{\text {post }}$ is the current gain after irradiation, $\beta_{\text {pre }}$ is the current gain before irradiation, $\Phi_{n}$ is the dose, and $f_{T}$ is the unit gain frequency.

Commercial devices often have a channel stopper or guard band to provide isolation between the adjacent devices. However, the threshold voltage of power MOSFET of this region is usually not sufficient to prevent the inversion in a radiation environment, and the guard band must be doped heavily enough to prevent the inversion after irradiation.

A simple method for estimating the threshold voltage shift [11] due to the ionizing irradiation of a low dose rate was proposed recently for MOSFET. Briefly, this method estimates the threshold voltage $\left({ }^{V_{T}}\right)$ shift by the oxide charge trapping at the gate oxide immediately after irradiation.

This paper presents the effects of various kinds of radiations in space environments that can cause the damage of electronic components. It is shown that the reference voltage and 
the threshold voltage in the electrical characteristics of PWM-IC are varied by the radiation effects in TID test at the low energy $\gamma$ rays using ${ }^{60}$ Co at Korea Atomic Energy Research Institute (KAERI) and SEL test by using the 4 heavy ions at Texas A\&M University Cyclotron Facility, USA.

\section{Radiation Effects of PWM-IC}

The most common of PWM-IC is to generate periodic waveforms with adjustable duty cycles. PWM-IC also provides optimized features for DC/DC converter as a switching regulator. The PWM-IC block diagram has an additional transistor and two resistors in the left side, which are designed in this paper, to the existing PWM-IC [12] for operating the DC/DC converter. The electrical characteristics of UC2846 PWM-IC have various parameters, the crucial two parameters for operating DC/DC converter are given in Table 1.

In order to check the operation of PWM-IC in Figure 3, it is tested that the output voltage of PWM-IC is linearly dependent on the pulse width for the given input voltage after the implementation as shown in Figure 4. The output voltage is produced from different stable DC input sources regulated by a bi-polar transistor. Pin 8 can be charged or discharged. The sensor amplifier can be seriously affected by the current flow when the input voltage of $12 \mathrm{~V}$ is directly attached to pin 4 . In order to make the effect of the sensor amplifier minimized and the PWM pulse stable, the voltage feedback circuit with a bipolar transistor is designed, and the specific voltage supplied to pin 4 is obtained through the regulated resistor. Then, the emitter of ${ }_{E}$ is obtained as follows.

$$
\mathrm{I}_{\mathrm{E}}=(1+\beta) \mathrm{I}_{\mathrm{B}}
$$

where $I_{E}$ is the base current and $\beta$ is the current gain. Pin 11 for the PWM-IC output is connected to a MOSFET driver, TPS 2813, from Texas Instruments, which is adaptable to IRF 3315S P-MOSFET. The waveforms of the output voltages were exactly produced based on the duty cycle, showing $6 \mathrm{~V}$ for $\mathrm{D}=0.5$ in Figure 5 and 3.6 for $D=0.3$ in Figure 6 , respectively, when the input voltage of $12 \mathrm{~V}$ is applied.

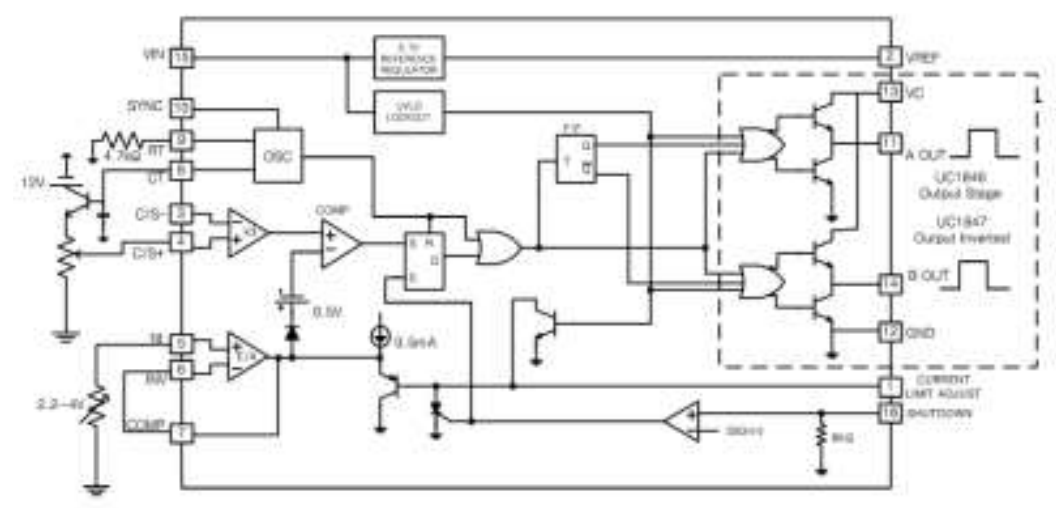

Figure 3. A PWM-IC Block Diagram with a Bipolar Transistor 


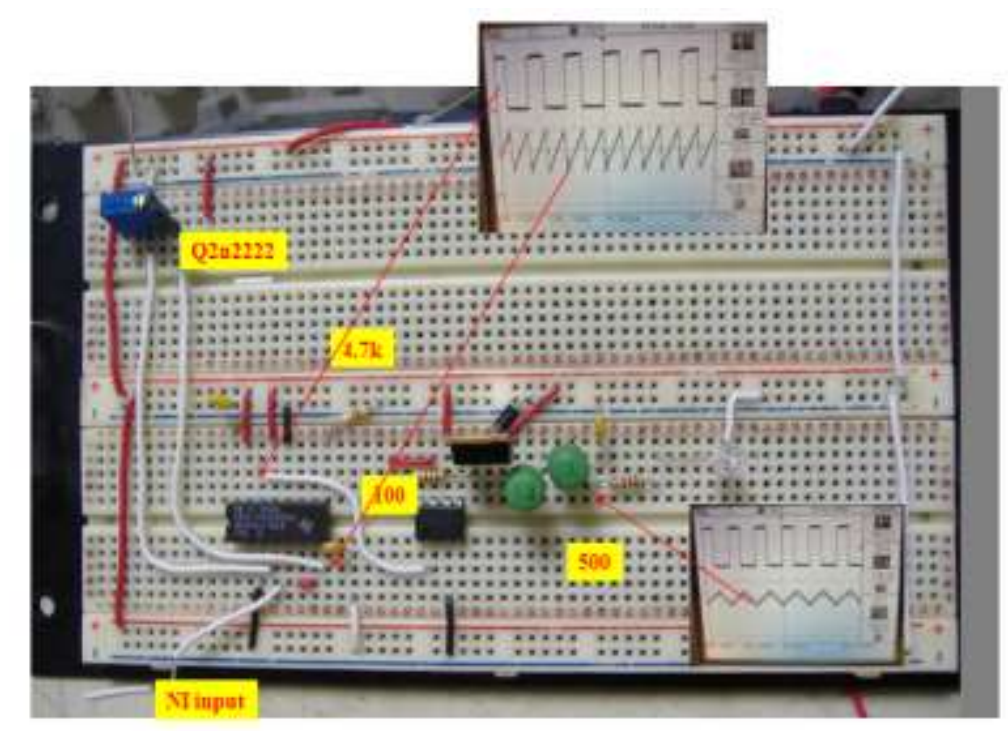

Figure 4. Implementation of DC/DC Converter with PWM-IC

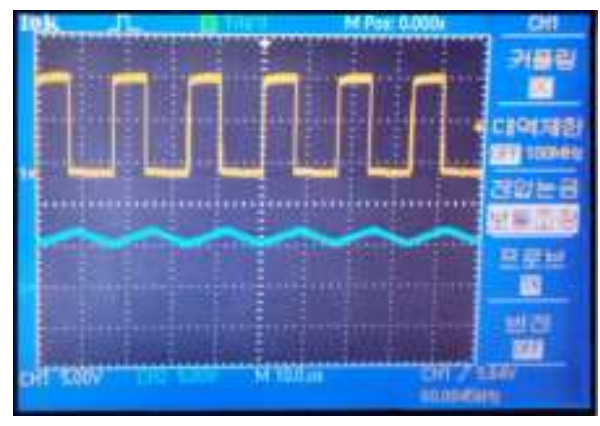

Figure 5. Output Voltage for $\mathrm{D}=0.5$

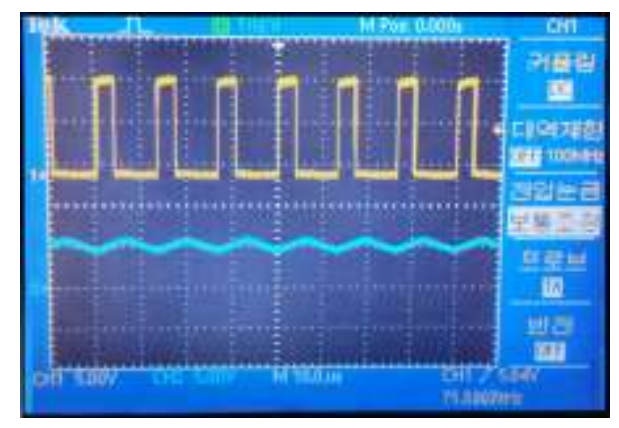

Figure 6. Output Voltage for $\mathrm{D}=0.3$

Table 1. Electrical Characteristics of PWM-IC

\begin{tabular}{|l|l|c|c|c|c|}
\hline \multirow{2}{*}{ PARAMETER } & \multirow{2}{*}{$\begin{array}{l}\text { TEST } \\
\text { CONDITIONS }\end{array}$} & \multicolumn{3}{|c|}{ UC2846 } & \multirow{2}{*}{ UNIT } \\
\cline { 2 - 5 } & MIN & TYP & MAX & \\
\hline Reference Section & 5.00 & 5.10 & 5.20 & $\mathrm{~V}$ \\
\hline $\begin{array}{l}\text { Output } \\
\text { Voltage }\left(\mathrm{V}_{\text {ref }}\right)\end{array}$ & $\begin{array}{l}\mathrm{TJ}=25^{\circ} \mathrm{C}, \\
\mathrm{I}=1 \mathrm{~mA}\end{array}$ & 250 & 350 & 400 & $\mathrm{mV}$ \\
\hline $\begin{array}{l}\text { Shutdown Terminal Section } \\
\text { Threshold } \\
\text { Voltage }\left(\mathrm{V}_{\text {th }}\right)\end{array}$ & - &
\end{tabular}

\subsection{Simulation of PWM-IC}

The simplified circuit [13] for the simulation of pulse missing transients is designed by using SPICE, as shown in Figure 7. The PWM controller works at a constant input voltage of $10 \mathrm{~V}$ and output voltage of $1 \mathrm{~V}$, using a switching frequency of $30 \mathrm{Khz}$, $\mathrm{D}=0.2, \mathrm{~V}_{\text {th }}=4.0786 \mathrm{~V}, \mathrm{R}=0.2 \Omega, \mathrm{R}_{\mathrm{F}}=10 \Omega$, and $\mathrm{C}_{\mathrm{F}}=47 \mathrm{pF}$. The output current is $5 \mathrm{~A}$. In steady state, the oscillated signal is being connected to the 'AND' gate, then the output is set to the input of R/S flip flop. When MOSFET turns ON, and the inductor is activated due to the voltage, then the currents increase as time goes on. As for the input of comparator, the voltage of $1 \mathrm{~V}$ is connected to the input '-' terminal with the voltage 
reference error, and the output of comparator makes R/S flip flop set. When the voltage of greater than $1 \mathrm{~V}$ is applied to the input '+' terminal of comparator, the output of comparator goes to 'high' state, which makes the R/S flip flop be reset and the MOSFET be turned OFF. Then, the inductor current flowing across the diode is in the freewheeling in the loop. The inductor current decays with time constant of 10,000 seconds by $\mathrm{R}_{\mathrm{L}}=10 \Omega$, and $\mathrm{L}=1 \mathrm{mH}$

When both the input of ' $\mathrm{s}$ ' at R/S flip flop and the output of comparator for the feedback voltage keeping greater than $1 \mathrm{~V}$ are ' $\mathrm{ON}$ ' state, the output of R/S flip flop turns to 'Inhibit' state. In order to prevent all 'High' from ' $Q$ ' and ' $Q B$ ', the ' $\mathrm{s}$ ' terminal of R/S flip flop is set to 0 , which is the output of 'AND' gate generated by reversing the output signal of comparator. Delay time is used to prevent 'reset' signal from initiating the output of comparator before the output of 'AND' gate fails to low state. The inductor currents are shown in Figure 8 through the simulation decay with time constants of about $0.25 \mathrm{~ms}$ for 5 missing pulses and about $0.5 \mathrm{~ms}$ for 10 missing ones. The more missing pulses lead to the slower decay. When the threshold voltage below $3.0 \mathrm{~V}$ produced by $V_{\mathrm{g}}$ is applied to MOSFET, it becomes sensitive to less noise and disturbance than normal, and it easily turns on. It is difficulty in obtaining a steady state constant current since the fluctuation of the output increases. The triangle signal of the $V_{\text {ref }}$ error in Figure 9 is applied to the reference input for making maximum voltage of $2 \mathrm{~V}$. The maximum output current is $10 \mathrm{~A}$. It is shown that the pulse width at the input node of MOSFET depends on the magnitudes of the inductor current and the reference voltage. The pulse becomes to wider as the inductor current and the reference voltage increase. The shape of reference voltage follows the waveform of the inductor current.

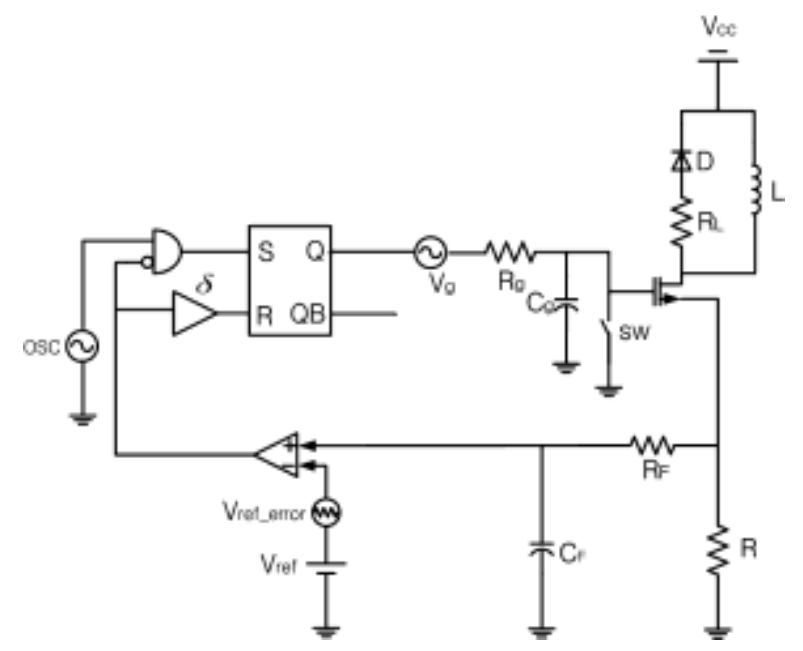

Figure 7. A Simplified PWM-IC Block Diagram for Simulation 


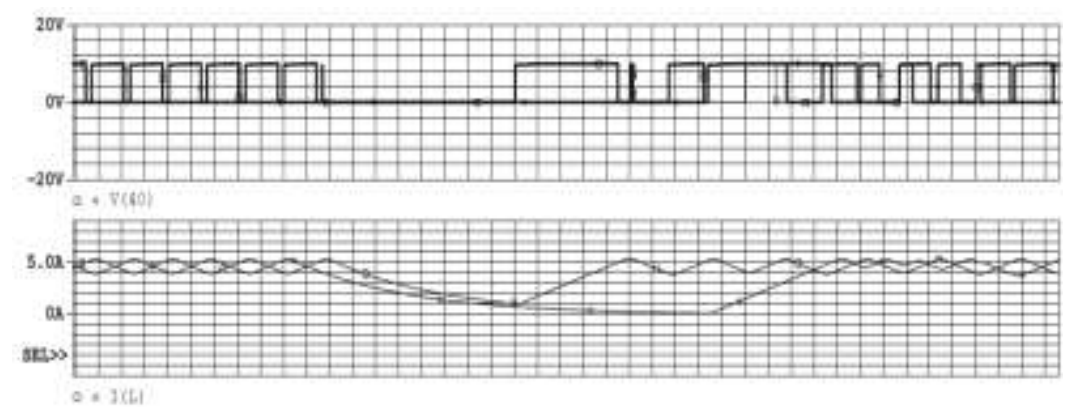

Figure 8. The Gate Voltage of MOSFET and the Inductor Current for Missing Pulses $\left(\mathrm{R}=0.2 \Omega, \mathrm{V}_{\mathrm{ref}}=1 \mathrm{~V}, \mathrm{I}_{\mathrm{L}}=5 \mathrm{~A}\right)$

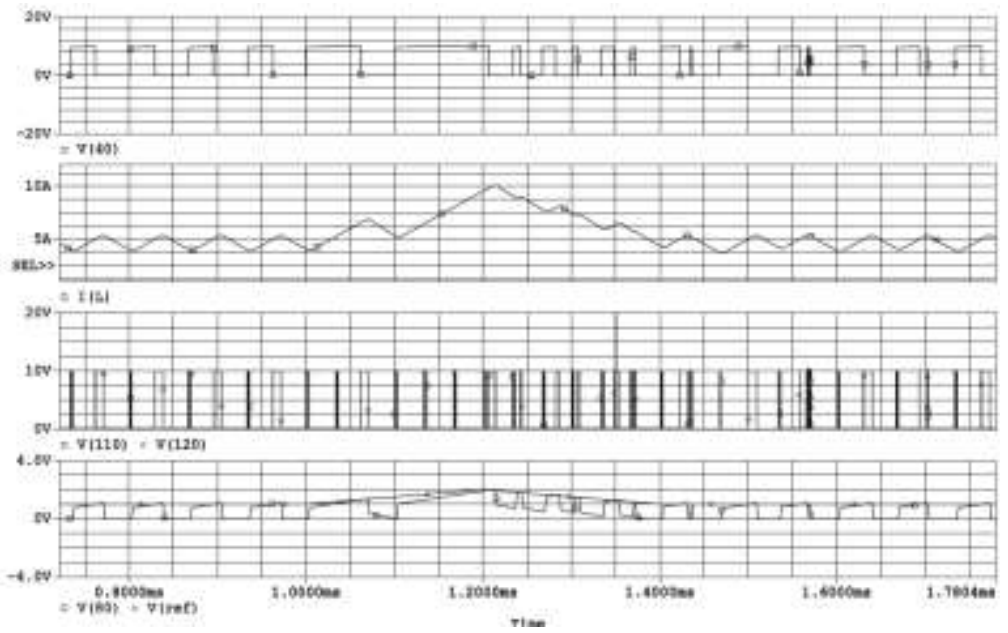

Figure 9. The Gate Voltage of MOSFET and the Inductor Current, the Signals of ' $S$ ' and ' $R$ ' at R/S Flip Flop, and the Voltage of Sense Resistor and the Reference Voltage $\left(R=0.2 \Omega, V_{\text {ref }}=1 V_{s} I_{L}=5 A\right)$

\subsection{TID Test}

TID effects are due to positive trapped charge and creation of interface traps in oxides. TID mainly increases leakage under isolation oxides and at the gate edges [14]. It creates a parasitic edge transistor with a threshold voltage $\left(V_{\text {th }}\right)$ which decreases with TID. The impact of TID is primarily on the IC leakage current. TID degradation is the cumulative long term ionizing damage to CMOS devices due to electrons and protons. The accumulated TID in silicon based microelectronics is usually quantified in units of Rad ( $\mathrm{Si}$ ) and is a measure of the energy stored in silicon by the ionizing radiation. The Rad is related to the Gray SI units given by

$$
1 \operatorname{Rad}=\frac{1}{100} \text { Gray }
$$

Ionizing radiation penetrates the CMOS materials depositing energy that lead to electron/hole pairs, which are abruptly separated by electric fields in the devices. A key parameter in the interaction of the ionizing radiation is the energy deposited per unit length of $\frac{d E}{d x}$. This parameter is named as linear energy transfer (LET) with units $\mathrm{MeV} / \mathrm{cm}^{2} / \mathrm{mg}$ given as

$$
\text { LET }=-\frac{1}{\rho} \frac{d E}{d x}
$$

where $\rho$ is the density of material. 
Silicon dioxide $\left(\mathrm{SiO}_{2}\right)$ is the predominant oxide for CMOS devices. Significant numbers of electron/hole pairs are generated by electrons and protons that are abundant in the Van Allen Belts. The total number of TID induced and trapped after carrier recombination and drift mechanisms that contributes to leakage is voltage bias dependent. To understand how the TID induced leakage mechanisms affect PWM-IC, PWM-IC fabrication and operation [15] should be investigated.

When radiating PWM-IC, the five factors of total dose, dose rate, exposure time, irradiation step, and test units for the test procedure are followed by MIL-STD-883 Method 1019.

A sample size of 6 pieces of PWM-IC is used for each test. The output voltages shown in Figure 10 of 6 PWM-IC's irradiated to the source using ${ }^{60} \mathrm{Co}$ are satisfied with the electrical specification up to $30 \mathrm{Krad}$ with dose rate of $5 \mathrm{rad} / \mathrm{sec}$, but the threshold voltages represented by Figure 11, which are a higher value than the criterion, are not met with the specification shown in Table 1.

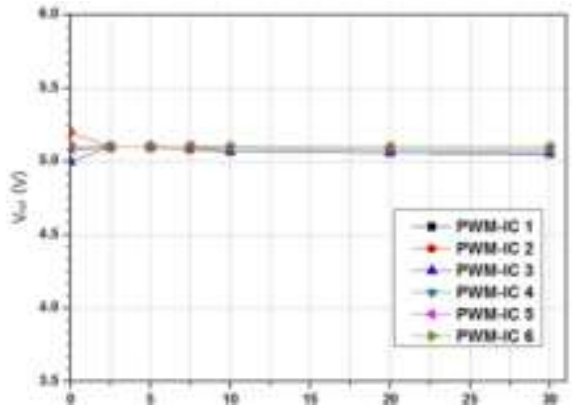

Figure 10. Output Voltage vs. Dose

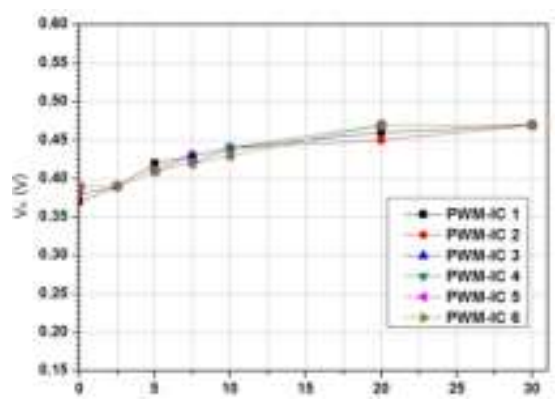

Figure 11. Threshold Voltages vs. Dose

\subsection{SEL Test}

Single Event Effects (SEEs) [16] are caused by a single, energetic particle, and can take on many forms. SEE is due to a heavy ion striking sensitive volumes of transistors in analog and digital circuits. As these phenomena typically do not affect permanent damage in circuits, which are called soft error (SE). A single more massive or higher energy ionizing radiation particle can directly affect the circuit state by causing a single event effect. Different failure modes from single event collected charge depend on the incident particle, the device physics of the devices and circuit types. The main collection mechanisms are drift, charge funneling and diffusion. The current waveform depends on the driving or restoring circuit. As the collecting node is driven to the supply rail, the diode is no longer at a favorable voltage to collect charge until sufficient charge has been depleted by the driver. Charge stored in the space charge depletion region is rapidly collected. The next most crucial abrupt collection mechanism is charge funneling in which the ion track distorts the electric field lines, and allows collection by drift beyond the depletion regions. The least important collection mechanism is diffusion since it is slower and diffuses the charge across more collecting nodes. When the charge is deposited by a storage node, which is called a latch or memory circuit, and there is sufficient charge to flip the stored state, the situation is a SEU. When the charge is collected by a combinational logic circuit, the voltage at that node is perturbed and the situation is a Single Event Transient. SEUs are soft errors, and non-destructive. Several types of hard errors, potentially destructive, can appear. SEL leads to a high operating current, above the device electrical characteristics.

For the SEL test of PWM-IC, 4 kinds of heavy ions with $15 \mathrm{MeV} / \mathrm{u}$ energy at Texas A\&M Univ. Cyclotron Facility are used. They are Kr (Initial LET (air) 26.6 $\left(\mathrm{MeV} / \mathrm{mg} / \mathrm{cm}^{2}\right)$, LET at Bragg Peak 41.4), Xe (Initial LET 49.3, LET at Bragg Peak 63.4), 
Ho (Initial LET 66.7, LET at Bragg Peak 79.2) and Au (Initial LET 82.8, LET at Bragg Peak 93.5). The SEL to each heavy ion does not occur within the irradiated duration for reaching within $10 \%$ tolerance of normal output value, the corresponding fluence is computed. The evaluation of SEE is usually measured by means of cross section curve. Cross section is defined as the likelihood of the energetic particle interacting with the atoms of material. It reflects the area of the device sensitive to SEE. Linear energy transfer (LET) is a commonly used concept in the SEE evaluation.

Angled strikes may allow more charge to be stored at a circuit node. The effective relation is given by

$$
L E T_{\text {eff }}=\frac{L E T}{\cos \theta}
$$

where $\theta$ is the angle at which the particle strikes the bare chip of PWM-IC with ${ }^{\circ}$ being orthogonal to the surface. ICs are generally ground tested in neutron, proton or ion beams to determine their susceptibility to SEE. The probability of hitting a target is measured by its distinct cross section given by

$$
\sigma=\frac{\text { errorse }}{\text { fluence }}
$$

where fluence is usually measured in particles $/ \mathrm{cm}^{2}$. Then, the result is an area with unit $\mathrm{cm}^{2}$ that represents the distinct size of the target. For heavy ions, the cross section is typically plotted versus LET with unit $\mathrm{MeV} / \mathrm{mg} / \mathrm{cm}^{2}$. The test results of SEL transients of PWM-IC of UC-2846 are shown in Table 2.

Table 2. SEL Transients of PWM-IC of UC-2846

\begin{tabular}{|c|c|c|c|c|c|}
\hline SAMPLE & $\begin{array}{c}\text { LET } \\
\left(\mathrm{MeV} / \mathrm{mg} / \mathrm{cm}^{2}\right)\end{array}$ & $\begin{array}{c}\text { Fluence } \\
\left(\text { ions } / \mathrm{cm}^{2}\right)\end{array}$ & $\begin{array}{c}\text { Cross } \\
\text { Section }\left(\mathrm{cm}^{2}\right)\end{array}$ & SEL EVENT & Remarks \\
\hline 1 & 40 & $1.50 \times 10^{8}$ & $6.67 \times 10^{-10}$ & Not occurred(10\% $\downarrow)$ & $24 \mathrm{~min} 06 \mathrm{sec}$ \\
2 & 40 & $1.83 \times 10^{8}$ & $5.46 \times 10^{-10}$ & Not occurred(10\% $\downarrow)$ & $50 \mathrm{~min} 45 \mathrm{sec}$ \\
\hline 3 & 57 & $2.85 \times 10^{8}$ & $3.51 \times 10^{-10}$ & Not occurred(10\% $\downarrow)$ & $49 \mathrm{~min} 28 \mathrm{sec}$ \\
4 & 57 & $3.03 \times 10^{8}$ & $3.30 \times 10^{-10}$ & Not occurred(10\% $\downarrow)$ & $43 \mathrm{~min} 55 \mathrm{sec}$ \\
\hline 5 & 69.1 & $7.10 \times 10^{8}$ & $1.41 \times 10^{-10}$ & Not occurred(7\% $\downarrow)$ & $23 \mathrm{~min} 40 \mathrm{sec}$ \\
6 & 69.1 & $5.34 \times 10^{8}$ & $1.87 \times 10^{-10}$ & Not occurred(5\% $\downarrow)$ & $12 \mathrm{~min} 20 \mathrm{sec}$ \\
\hline 7 & 90 & $4.40 \times 10^{8}$ & $2.27 \times 10^{-10}$ & Not occurred(10\% $\downarrow)$ & $39 \mathrm{~min} 38 \mathrm{sec}$ \\
\hline
\end{tabular}

Note: $10 \% \downarrow$ indicates $10 \%$ decrease of waveform frequency, $24 \mathrm{~min} 06 \mathrm{sec}$. means the duration of flux applied.

The cross section versus LET of PWM-IC is obtained as shown in Figure 12. The equation between cross section and fluence is represented by,

$$
\sigma\left(\mathrm{cm}^{2}\right)=\frac{1}{\text { fluence }}\left(\text { ions } / \mathrm{cm}^{2}\right)
$$

The value of cross section is converged to below $1 \times 10^{-8}\left(\mathrm{~cm}^{2}\right)$ 


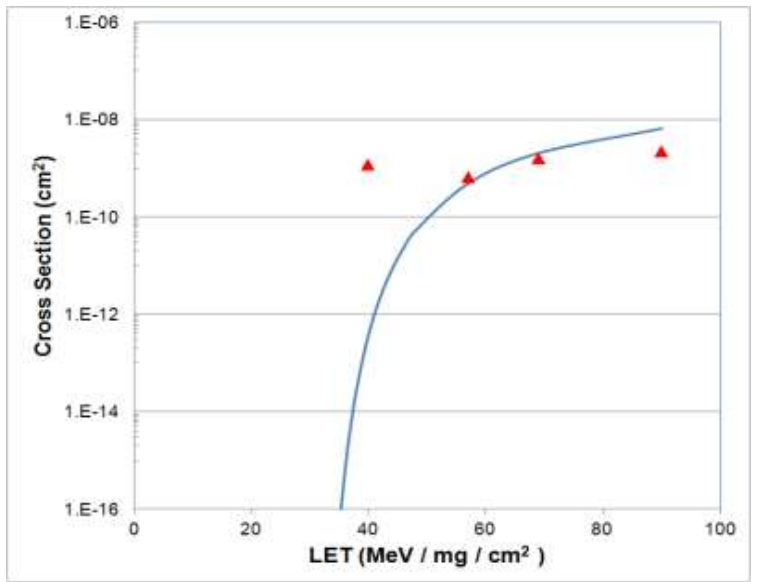

Figure 12. Cross Section vs. LET of PWM-IC ( $\triangle$ : Transient Capture, $\mathrm{LET}_{\text {th }}=$ $36 \mathrm{MeV} / \mathrm{mg} / \mathrm{cm}^{2}$ )

\section{Conclusions}

The radiation effects of a designed PWM-IC module were simulated by SPICE, and the phenomena originated from missing pulses and the change of offset voltage at error amplifier is analyzed. The implementation of a macro model of PWM-IC should be considered to prevent the shift of threshold voltage and the error voltage, and the missing pulses for obtaining the steady state current. In TID tests, the output voltages and the threshold voltages, two important characteristics of the electrical specifications for 6 PWM-ICs, are experimented for the radiation source using ${ }^{60} \mathrm{Co}$ with dose rate of 5 $\mathrm{rad} / \mathrm{sec}$ up to total dose of $30 \mathrm{Krad}$. The output voltages are satisfied with the specifications, but the threshold voltages show a $10 \%$ higher value than the criterion, which are not met with the specifications. It is estimated that SEL tests to get cross section versus LET by using 4 heavy ions at the Cyclotron Facility, which are not available in Korea, are successfully carried out, and the test procedure and method can be contributed to radiation hardening technology in Korean industry fields.

\section{Acknowledgments}

This work was supported by Institute for Information \& Communications Technology Promotion (IITP) grant funded by the Korea government (MSIP) (No. B0186-16-1001. Form factor-free Multi-input and output Power Module Technology for Wearable Devices).

\section{References}

[1] J. Barth, "Modeling Space Radiation Environments", IEEE 1998 NSREC, (1998).

[2] S. H. Lee and J. Y. Jung, "Power Electronics Engineering", Seoul: Hyung Seol Publication Inc., (in Korean), (2010), pp. 143-153.

[3] C. J. Woong and S. H. Jung, "Design of a CCM/DCM dual Mode DC-DC Buck Converter with Capacitor Multiplier", Journal of the Korea Academia-Industry Cooperation Society, (in Korean), vol. 17, no. 9, (2014), pp. 21 26.

[4] S. H. Sik, L. M. Ji, P. W. Kyung and S. H. Jung, "Design of a DC-DC Step-Down Converter for LED Backlight of Mobile Devices", Journal of the Korea Academia-Industry Cooperation Society, (in Korean), vol. 15, no. 3, (2014), pp. 1700-1706.

[5] Y. H. Lho, “A Study on the Design of a Pulse-Width Modulation DC/DC Power Converter", Int'1 J of Aeronautical Space Sci., vol. 11, no.3, (2010), pp. 201-204.

[6] N. J. Hoon and S. H. Jung, "Design and Analysis of a 12 V PWM Boost DC-DC Converter for Smart Device Applications", Journal of the Korea Academia-Industry Cooperation Society, (in Korean), vol. 17, no. 6, (2016), pp. 239-245. 
[7] T. D. Hyun, P. J. Byom, K. M. Young, C. S. Sik, K. C. Hyuk and N. D. Suck, "A Study on the Efficiency Improvement Method of Photovoltaic System Using DC-DC Voltage Regulator", Journal of the Korea Academia-Industry Cooperation Society, (in Korean), vol. 17, no. 7, (2016), pp. 704-712.

[8] N. W. Van Vonno, L. G. Pearce, G. M. Wood, J. D. White, E. J. Thomson, T. M. Bernard, P. Chesley and T. Hood, "Total Dose and Single Event Testing of a Hardened Single-Ended Current Mode PWM Controller", presented at NSREC2010, (2010).

[9] Cadence Design Systems, SPICE Reference Guide, San Jose, CA: Cadence Design System, Inc. (2010).

[10] J. Schwank, "Total Dose Effects in MOS Devices", IEEE Nuclear Space Radiation Effects Conference, Short Course III-47, (2002).

[11] Y. H. Lho and K. Y. Kim, "Radiation Effects on the Power MOSFET for Space Applications", ETRI Journal, vol. 27, (2005), pp. 449-452.

[12] "Datasheet of UC 1846, 2846", Texas Instruments, (2002).

[13] Y. H. Lho, S. Y. Lee and J. D. Kim, "A Study on the Characteristics of the Irradiated Current Mode PWM Controller", Proceedings of the 9th International Workshop on Radiation Effects on Semiconductor Devices for Space Applications, Japan, (2010), pp. 191-194.

[14] L. T. Clark, "Microprocessors and SRAMs for Space: Basics, Radiation Effects and Design", 2010 IEEE NSREC Short Course, (2010).

[15] L. J. Kyung and S. H. Jung, "Design of a Step-up DC-DC Converter using a $0.18 \mu \mathrm{m}$ CMOS Process", Journal of the Korea Academia-Industry Cooperation Society, (in Korean), vol. 17, no. 6, (2016), pp. 715-720.

[16] "Radiation Effects \& Analysis", radhome.gsfc.nasa.gov, (2015).

\section{Authors}

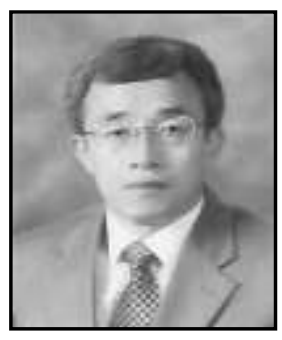

Young Hwan Lho, received the BS degree in electronics engineering from Kyungpook National University, Daegu, Rep. of Korea, in 1982; his master degree from University of New Mexico, Albuquerque, NM, USA, in 1988; and his PhD degree from Texas A\&M University, College Station, TX, USA, in 1993, all in electrical engineering. From November 1981 to December 1985, he was an engineer with LG Information Communication Co., Ltd., Seoul, Rep. of Korea, working on parts localization for Electronic Switching System. From February 1994 to February 1995, he was a senior researcher with Korea Aerospace Research Institute, Daejeon, Rep. of Korea, working on Satellite Attitude Control. Since March 1995, he has been with Woosong University, Daejeon, Rep. of Korea, where he is a professor. His research interests include power electronics design, power circuit design, and automatic control for system.

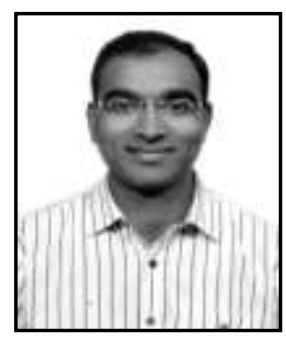

Surender Reddy Salkuti, received the Ph.D. degree in electrical engineering from the Indian Institute of Technology, New Delhi, India, in 2013. He was a Postdoctoral Researcher at Howard University, Washington, DC, USA, from 2013 to 2014. Presently, he is working as an Assistant Professor in the Department of Railroad and Electrical Engineering, Woosong University, Daejeon, Republic of Korea. His current research interests include power system restructuring issues, congestion management, market clearing including renewable energy sources, demand response, smart grid development with integration of wind and solar photovoltaic energy sources, artificial intelligence applications in power systems, and power system analysis and optimization. 
International Journal of Control and Automation Vol.10, No.6 (2017) 